\title{
Geeks and Battlers: \\ Intersections of Generic Specificity and National Narrative in Writing Australian Science Fiction
}

Sylvia Kelso

James Cook University—Townsville

Three or four years ago I gave a paper at ICFA on the theoretical problems on race, in particular, that I foresaw in writing a work of Australian SF (Kelso, "Aliens"). Two years ago I used another paper to consider how you actually define SF. This is a field report, so to speak, on what writing the novel showed me about the SF genre, especially as its specificities intersected those of Australian narrative in "Australian science fiction."

In 2000 I had gathered a roughly consensual but longterm definition of SF by content. For Hugo Gernsback it was "a charming romance intermingled with scientific fact and prophetic vision (Clute and Nicholls, 311). Joanna Russ considered that it "shows things not as they ... are but as they might be, and for this "might be" the author must offer a rational, serious, consistent explanation (79). Brooks Landon declared succinctly that, "Science fiction is the literature of change. (xi) Samuel Delany, however, says flatly that SF:

is not about the future; it uses the future as a narrative convention to present significant distortions of the present. (47).

Beyond what Fredric Jameson has called "the older interpretation" of a genre, by what it means (108), these were all insiders' views, and they took the genre seriously. In strong contrast, many people outside the field dismiss SF as non-realist, escapist, and Not Serious: the homeground of Bug-Eyed Monsters and Little Green Men.

I also looked at what Jameson calls the genre as social contract (106): that is, what readers and writers agree is or is not, in this case, SF. I've looked particularly at audience expectations of the genre, and with this, what Jameson calls the more recent critical approach of asking how a genre works (108). And asking how SF works and what its audience expects brings us instantly to "sensawunda" - that most ironised cliché in SF. 
If we reconsider "sensawunda," we find, first, that it remains a watchword of SF reviews, titles, and cover blurbs. “Astounding Science Fiction, Amazing Stories, Women of Wonder, Anatomy of Wonder, "one enormous sense of wonder" (Stith) "lots of sense-ofwonder" (Review, Melissa Scott, Dreamships), "Beauty, terror and wonder” (Brust). (Kelso, Singularities, 151). Nor is this a superficial attribute. It suggests, rather, that the SF audience composes what a librarian has conveniently called Type B readers - those who want "total departure from the known world" (Tyson, qtd. Bujold, 157).

Beyond the longstanding assumptions that the SF audience is white, male, middleclass, interested in science (Klein), and, nowadays, getting old (Hartwell, 1 ), some of the few hard figures on readership add interesting nuances. Surveys of Mid-Western US conventions around 1980 indicated that of 700 participating fans $45 \%$ were women, and $67 \%$ below thirty. $65 \%$ had some college education, 30\% had bachelors' degrees. Over $90 \%$ were Caucasian, $49 \%$ called themselves loners, and $62 \%$ were oldest or only children (Day and Day, 95-96).

I emphasise these last figures, firstly because they gave me a sense of recognition, and further, because it is echoed by nearly every SF reader I show them to. Again, this is not merely an interesting attribute. It suggests rather a point at which constructions of genre by content and operation are integrally entwined. This integration is most easily described via the concept initiated by Levi-Strauss, of narrative as myth - that is, neither legend nor falsehood, but a story told to make sense of cultural phenomena. And given the indicated audience, one may propose that, if detective novels are narratives of the Law, and female romance narratives of Marriage, SF stories are narratives of the Geek.

Again, at first glance, this sounds either superficial or obvious. But think a little further. What is a geek? Geeks are not sociopaths, but neither are they socially desirable. Their clothes are "off." Their interests are esoteric, and can be superior to the point of jealousy. Usually they are loners, nearly always readers, often "know-it-alls." Very often they have connections to science. It should be noted, however, that this profile does not match the politicized differences of race, sexuality, ethnicity, or even class. Blacks are not geeks, although Jews may be. Nor are gays, except when their sexuality is submerged, and neither are Hispanics in the US, or Thais or Vietnamese in Australia, nor, usually, those who are overt working class. Geekness is rather a marker of difference within the hegemonic white middle-class ambience. And this is precisely the area of the SF audience. 
And the SF community flaunts its geek-hood. SF conventions produce large numbers of people who, without dressing as Darth Vader, show common signs of geekish difference: unrepentantly long unstyled hair, varying degrees of excess weight, New Age dresses or battered jeans and exotic SF-oriented T-shirts. It all defiantly announces: I am not habitually a short-back-and-sides person, a suit-person. I am different.

Again, this appeared fairly superficial, until I applied the concept to SF texts. And then a demographic peculiarity reappeared as the cultural side of a feedback loop that runs through both film and fiction, into most eras and nearly all national bodies of SF. As a starting point, many SF critics and readers consider the essential SF narrative to be A.E. Van Vogt's story, "Slan" (1953). But the Geek had long since appeared memorably with Shelley's monster in Frankenstein (1818), to recur through Verne's eccentrics like Nemo or Phileas Fogg, C.S. Lewis's linguist Ransome, and the work of John Wyndham, as in Chocky (1968) or TheChrysalids(1955). Across the Atlantic, there is Theodore Sturgeon's More than Human (1953). The figure is as easily identified in Stranger in a Strange Land (1961) as with Frank Herbert's original conservationist in Dune (1965). It re-emerges overtly with Gibson's Case in Neuromancer (1984), and since 1985 has had a triumphantly rewarded reign with Lois Bujold's hero, Miles Vorkosigan. It is satirized in Connie Willis' story of double-geekhood, “And Come From Miles Around"(1979), and triumphs happily in recent films like The Matrix (1998) or, with charming self-reflexiveness, in the human and alien geeks of Galaxy Quest(1999).

Unlike the detective novel, the narratives of geekdom are not a single fabula. They may end, like Frankenstein, with difference's isolation and tragedy. They may end, as in Galaxy Quest, with Geeks Saving the World. Or, as in Wyndham's and Sturgeon's texts, geeks may find or found communities of their own. Geek protagonists are very often scientists, but they are geek scientists: outsiders, or champions of some apparently lunatic idea. While Dr. Strangelove is a dangerous geek, Contact (1997) offers a more central version: a scientist and a project ridiculed by the orthodox, in or out of science, that make triumphantly good.

The narrative's cultural sources are almost as obvious as the hegemonic nature of its white middleclass ambience. SF is currently, by weight of production, writers and readers, a predominantly American genre. Critics from Leslie Fiedler to the Australian Graeme Turner have looked at US myths - again in the cultural studies sense - and distinguished one of the most important, faith in the "innocence of the American Adamic hero" (Turner 77) and the 
individual self (Lewis and Fiedler qtd. Turner 76-7). To this we may add the influence of what Andrew Ross calls the positivist "religion" of science in the 1920s and '30s (105), which so deeply influenced the SF community, through to the "40s, the Golden Age of SF. This faith lingers, in the tangential but powerful input of NASA's "can-do" ethos, and the influence of NASA noticed, for example by Constance Penley, in the mass TV audiences of Star Trek. Despite the persistent dystopic, indeed paranoid element in SF, and the disillusionment of the Atomic era, the SF Zeitgeist might still be read, overall, as one of optimism and expectance of success.

In contrast, critical formulations of Australian national narratives focus on two important aspects, the landscape, and the protagonist. And most importantly, in contrast to the SF geek, the Australian protagonist is, according to Tom Ryan,

a battler against overwhelming odds which cannot be defeated even if they are confronted head-on, but which will allow survival if he/she suffers the indignities without asserting resentment. (qtd. Turner, 58).

While most Australians invest the image of "the battler" with vague approval, to Graeme Turner, this defeat becomes a

respon[se] to a secularised and alienated environment by admitting the withdrawal of meaning and value, but without inventing a replacement for which he may accept responsibility. (9)

Moreover, this is underlain by "an ideological proposition that ... legitimates powerlessness and subjection" (9-10).

The mask for this ideological proposition is most often the battler's chief opponent. In Australian narrative, says Bruce Clunies Ross, "the starring role is taken by the great Australian landscape" (225). And it is a tradition old as white occupation to depict Australia overall as a "harsh, unforgiving landscape and climate" (Myers, 9), or as the early desert explorers complained, a fickle old hag, "barren and past her time" (Haynes, 52). At the mythic level discussed by David Myers, this landscape is central to Australian identity, since its trials produced the triumph of mateship and the heroic Australian bushman or Anzac (Myers, 7-9). Beyond this point, however, "the land" assumes varying inflections. 
As Turner points out, harsh Nature can stand for a harsh society, thus removing the imperative to change it (84). This allows two or three narrative responses, which Roslynn Haynes derives from the impact of $19^{\text {th }}$ Century exploration narratives: particularly, the combination of a national need for heroes and the disappointing inland explorations $(27 ; 58$ 9). Firstly, the protagonist is defeated, destroyed by the land's aridity. While this originally shifted the focus to explorers' heroic sufferings (Haynes, 111-14), it can also make the land a metaphor for Australian society as a spiritual desert, a treatment common in high fiction of the " $50 \mathrm{~s}$ and ' $60 \mathrm{~s}$. Alternatively, as Turner puts it, protagonists can find in the land "a unique natural beauty," and/or a "certain spirituality." Or they can master the "pioneering virtues of endurance and acceptance" (28). In a further evolution, the land becomes the superior binary of the corrupt and decadent city, a source of recovered spirituality. This, too runs back through Patrick White's work to the $19^{\text {th }}$ Century ballad contests of Paterson and Lawson, making the land, as adumbrated by Myers, the foundation of Australian integrity.

From Marcus Clarke's For the Term of His Natural Life (1874) to Peter Carey's The Tax Inspector (1991), then, Australian narratives present an individual in conflict with a harsh and unforgiving setting, whether it be urban or rural, social or natural. This is not, in fact, so different from SF. Though usually considered an urban genre, SF has constructed a wide range of environments, from the harshest post-Holocaust societies and prison planets to the liquid potential Edens of Slonzcewski's A Door into Ocean (1986) and Alison Sinclair's Blueheart (1996). Again, such environments can be friendly or hostile, but as might be expected from narratives of geekdom heavily indebted to science, they do not, as a rule, overcome or overwhelm the protagonist. Indeed, the epitome of SF's relation to its non-urban setting might be the mammoth terraforming project of Kim Stanley Robinson's Mars series. As might also be expected of a genre with colonial roots, such conquests of the environment are rarely questioned ethically.

The central difference between SF and Australian narrative, then, turns on the relationship with the environment, and its effect on the protagonist. And in contrast to the US myths, Australian narratives are tales of loss and alienation rather than success. Clearly, such patterns of hopelessness will cut across the optimistic geek narratives of SF.

We come now to the practitioner's report on testing these hypotheses. Beginning the SF novel, I did not know the critical consensus on Australian narrative, but I had spent considerable time on the theoretical differences between SF and fantasy, and without opening 
that incorrigible can of worms, I had a working writer's sense of the difference. I had already written several novels set in an Ur-Australian setting which I unhesitatingly classified as fantasy: their societies were pre-industrial, and the ennabling device for their non-realist events was magic, rather than any form, however pseudo-scientific or extrapolative, of science.

The first paragraph of this novel, which came from the seed-image dream - so very reminiscent of Mary Shelley's Genesis myth - was another matter. Though clearly about something unlikely, it invoked the names of Schroedinger and Hawking, and it sketched the discourse of a classical archaeologist. With some shock, I realized it was not fantasy. It promised to be a blend of realism and science fiction, neither of which I had ever attempted before.

I then discovered what I understood as a writer, rather than a critic or theorist, to be the nature of science fiction. In fantasy I had cheerfully invented an Ur-Australia which incorporated the Mountains of the Moon and the African Rift valley, and which had no northern sea boundary. If it relied on echoes of real cultures or landscapes, I had felt free to alter that material however I chose, and taken that freedom as the genre's highpoint. But I had also read Ursula Le Guin's caution on world-building in SF:

As soon as you... have said 'The green sun had already set, but the red one was hanging like a bloated salami above the mountains,' you had better have a pretty fair idea in your head concerning the type and size of green suns and red suns... and the arguments concerning the existence of planets in a binary system, and the probable effects of a double primary on orbits, tides, seasons, and biological rhythms... if you're bored by the labour of figuring [these details] out, then surely you shouldn't be writing science fiction. (“Cosmology," 122).

For such painstaking attempts to embed outrageous what-ifs in wide-ranging science-based verisimilitude, I seriously doubted my expertise.

At first acquaintance, then, I was taking SF on the valuation of its insiders: a serious genre, concerned with scientific knowledge and plausibility, the Superior Other of fantasy. This impacted immediately on my writing techniques. Firstly, I felt the need to research every proposition, because this background material had to be "accurate." Ironically, it had to be 
"real." And I was hung up for an entire twelve months while I tried to work out a "real" academic record for that putative classical archaeologist.

At the same time, consciousness of genre impacted on the novel's basic plot propositions. The dream had offered me the image of someone picking up precious debris at the foot of columns in a ruined ancient city on a hill in North Queensland. In fantasy, I would have explained its presence by some pretty hand-waving, a trip through the back of a wardrobe or the second file of a library. If this was SF, how was I to explain it in even superficially scientific terms?

The consequence was a pair of outrageous propositions: firstly, that the city was Macedonian, because Alexander never went to China, but he never turned back in India. And secondly, to support the first, drawing on quantum theory, that in Everett's multiple-choice universes, somewhere, Australia never fell off Gondwana, but remained joined to Africa and India.

This rebounded further on my writing techniques, since my sense of SF demanded I check the background out with geologists, botanists, and a genuine quantum physicist, who used his theory to offer propositions wilder than I ever dreamed. And the novel itself became selfreflexive. I ended up substantiating the secondary world by having the narrator put my questions to geologists, botanists and quantum physicists. The final chapter then produced an intellectual as well as emotional closure: the explanation that the opening paragraph demanded, within the grounds of scientific plausibility.

As a working writer, then, my understanding of SF turned on its "serious" nature, its reliance on "real" science, and the necessity to incorporate this science into the text. At the same time I had a firsthand experience of that fabled SF feature, the "what-if?" And for me SF was not so much an extrapolative use of science as a gay contradiction of scientific rules. Alternate worlds exist, says Everett's theory, but humans can't travel between them. Yes, my novel retorted, but what-if they could? The science was not to prove it possible, but to make the postulation as convincing as possible. Moreover, I realized, it was the same technique SF writers used with rocket travel before it became a reality, and with FTL flight when it is still an unreality. SF appeared not so much the scientific extrapolation of an unlikely possibility, as the application of science to garnish a plausible impossibility. 
Only with to the research component of the thesis did I re-cognise - in the most literal sense SF as a narrative of the Geek. And then I realized that the genre had already, and far less consciously, affected my protagonist.

As a conscious theoretical agenda, if the novel was to be quasi-realistic, I wanted it to engage issues in contemporary Australian society. As a black Welshwoman, who could look part Aboriginal, my classical archaeologist was formulated to raise the wakeful specters of Australian racism. As a more practical if not consciously planned point, I needed an outsider to explain Australia to an American audience. At a more generic level, I wanted such an outsider to provide not only SF's cognitive estrangement, but also, and very consciously, a sense of wonder about a landscape I personally found both exciting and beautiful. In this, at least, reader response to the ms suggested some success. For one of my friends, the depiction of the primary world produced:

A kind of wonder at ... Tville/Iville through your eyes. You have a way of...sumptuously looking at the world. It's a real overflow of senses. (A. Hosth, E-mail, 25.11.99)

To reach this protagonist, however, I had to use my sense of the genre for and against itself. I wanted a realistic academic background, but historically, the degree she needed, at the time, simply did not exist. However, the genre also offered freedoms impossible in realism. Let the primary world, I decreed, be another alternate, a situation marked by one simple landmark: Princess Di didn't die, she became Queen of England. And in this world, my protagonist could get a degree when I needed it.

This reacted almost instantly on both setting and protagonist. Most crucially, the protagonist instantly became an SF geek. I took her to North Queensland by raising the possibility of a Greco-Roman wreck on the Barrier Reef. Since she already had a degree in marine archaeology at an impossible time in "reality" I could easily make her topic another possible classical wreck, that disappeared before it could be authenticated. This set her up as both a national outsider and a stormy petrel, at odds with her profession and the academic establishment, and in perfect accord with the profile of the protagonist in Contact: a geek scientist, obsessed with an apparently loony project that, in the end, makes triumphantly if unrealistically good. 
How did these SF specificities interact with the characteristics of Australian narrative? Mostly, it appeared, SF prevailed. The landscape in my text was authentically hot and humid North Queensland, but it was by no means the harsh arid desert-based interior of classical Australian narrative. Moreover, the usual Australian binary of decadent coastal strip and arid but spiritually superior inland did not work. Both my settings were urban, both were coastal, and both, at one time or another, functioned as the classical settler's vision of Australia as an Antipodean Underworld (Turner, 52). But if the landscape won the battle in the secondary world - the ruins of the dream-city did appear - it was very far from doing so in the primary. This in turn changed the profile of the protagonist. She did not lose overall, did not leave the country, which is Graeme Turner's best possible outcome for an Australian battler, and certainly did not resign herself to defeat against overwhelming odds. Indeed, the outcome in both worlds left her with moral superiority if not outright victory.

However, if SF over-wrote the more negative aspects of Australian national narratives, I was far less happy with my efforts to overcome SF's own colonial hangovers. In particular, I could not make the narrative resist SF's tendency to unconscious racism. Like Samuel Delany trying to get women into classic SF narratives in the "60s, I found the "“natural workings"" of the story (McCaffery, 96).kept pushing my protagonist back into white orbits. I could not make her possible Aboriginal looks anything more than an opening gambit, I could not introduce important Aboriginal characters in the primary world, or give them more than fleeting prominence in the secondary world. I consider, overall, that this was less the prevailing quality of realism - black people do not, in fact, hold many positions of authority in Australia - than a failure of imagination.

Again, while I could identify the colonial narratives in SF: exploration, first contact, settlement, colonization, imperial dominance or decay, I could not work out a new form of the imperial narrative that the original dream imposed. If the ruined city was a Macedonian colony, what different sort of ending could it have? One that did not blame its fall on natural forces - another Australian copout - or, even worse, produce a compensatory story of indigenous battle and victory that would only put the Aboriginals in symbolic position as the land, thus avoiding all imperial blame? Was the only alternative to let the city survive, and thus outright endorse colonialism?

In the pilot paper, I admitted that I had no idea how to solve that dilemma, and in practice, I found the best I could do was deny closure - the novel refuses to say if the city actually was 
destroyed - while doing my best to put the blame for its possible destruction squarely on the colonists. In this case, I had them cling to outworn colonial shibboleths, disregarding the protagonist's warning of disaster. This left her uncomfortably close to the stereotypic role of a female Cassandra, though I did have her help her particular friends escape both their trammeling society, and its possible ruin.

It appears, then, that the generic demands, limits and freedoms of SF triumphed over those of national narrative. Is one to consider this a heartening turn away from pessimism in Australian fiction, a sign of national evolution, or another form of cultural imperialism?

I was, at first, inclined to the last answer, especially considering how poorly I combated the theoretical problems of SF. But analyzing the text, I found a couple of anomalous cases where it seemed the SF form had not so much suppressed as allowed the development of a national voice. The first was when the protagonist reflected on the Macedonian colony and nation as a mirror of Australia and England. In an ironic manner, she considered the Macedonian faction who wanted to go "home" - drawn directly from the demands of Alexander's soldiers in India - in tandem with the habit of older Australians to call England "home." It was not a view she considered kindly, given the response of many English to "colonials."

This echoed the attitudes mapped in late $19^{\text {th }}$ Century Australian nationalism: defensive, hostile to England, and very aware of its supposed inferiority. Later, however, the Macedonian colonists speak of going home because "this is not our land." And at this point the protagonist adumbrated a different nationalism:

This is not our land. I had heard my own parents say it, immigrants, transients, who came for what the country would give them and took those gains back to their own place. Like so many before them, all colours and races, who came for the gold, as they had to Blackston, and tore it out of the earth and left. Or later generations who cut down trees or devastated the natural habitat, getting what they could out of it, with no concern for tomorrow. Because it was not theirs.

In part this is the anger of Anglo-Celtic settler stock against later migrants who find Australia ugly and unhospitable. But it also speaks a sense of loyalty that supersedes the images of Antipodean purgatory, without stereotyping the land as harsh physical environment or 
spiritual sanctuary. It does show the ecological awareness that Clunies Ross finds in Australian consciousness as early as the '30s (232), which has increased with global green movements. I realized with some surprise that the impulse to escape SF's colonial plots, and the development of an imperialist critique, had resisted generic specificities far enough to give my protagonist, however fleetingly, however anomalously, the voice of an Australian rather than a Geek.

The field report then, says that an understanding of SF developed from prior, unexamined but insider's conceptions lays heavy emphasis on science, not only to help the impossible achieve audience credibility, but as an internal imperative. It suggests that SF's strength comes from an active sub-culture or community, that its readers identify with the genre figure, the Geek. Despite this narrow base, SF is a strong genre, that can override non-American nationalisms, but resists attempts to escape its colonial heritage. This is especially the case, it appears, not surprisingly, for those who, like myself, belong in the Geek's white, middleclass ambience. But if one takes the definition of "battler" closer to contemporary non-critical Australian understanding, then the fleeting national voice in my writing indicates a deeper fusion. For a battler now draws together connotations of a hardluck struggler and a "character," a tolerated oddity. And as it is a reputed Australian tendency to back the outsider - in both SF and racing terms - it is an Australian dream, derided, muted but enduring, that sometimes, however slightly, however ironically, the battler wins.

\section{Works Cited}

Bujold, Lois. “Mind Food: Writing Science Fiction.”Journal of Youth Services in Libraries 10.2 (1997): 157-67.

Clunies Ross, Bruce. "Landscape and the Australian Imagination." Mapped but not Known: The Australian Landscape of the Imagination. Eds. P.R. Eaden and F. H. Mares. Sydney: Wakefield, 1986. 224-43.

Clute, John, and Peter Nicholls, eds. The Encyclopedia of Science Fiction. Second edition. London: Orbit, 1993.

Day, Phyllis J. and Nora G. Day. "Freaking the Mundane: A Sociological Look at Science Fiction Conventions, and Vice Versa." Patterns of the Fantastic. Ed. Donald M. Hassler. Mercer Island: Starmont House, 1983. 91-102. 
Delany, Samuel R. "Some Presumptuous Approaches To Science Fiction.” Starboard Wine: more notes on the language of science fiction. New York: Dragon, 1984. 46-55.

Hartwell, David. "Blood of Roses, etc." E-mail to the author. 24.7.98.

Haynes, Roslynn D. Seeking the Centre: The Australian Desert in Literature, Art and Film. Cambridge: Cambridge UP, 1998.

Jameson, Fredric. The Political Unconscious: Narrative as a Socially Symbolic Act. London: Methuen, 1981.

Kelso, Sylvia. "Singularities: The Interaction of Feminism(s) and Two Strands of Popular American Fiction, 1968-89.” PhD. Thesis, James Cook University of North Queensland, 1997.

---. “"These are Not the Aliens You're Looking For': Reflections on Race, Writing and Theory in Contemporary SF." Flashes of the Fantastic . Ed. David Ketterer. Bowling Green: Greenwood Press, forthcoming.

Klein, Gerard. "Discontent in American Science Fiction.” Science-Fiction Studies 7 (1977) 313.

Landon, Brooks. Science Fiction After 1900: From the Steam Man to the Stars. New York: Twayne, 1997.

Le Guin, Ursula K. "Do-It-Yourself Cosmology." The Language of the Night: Essays on Fantasy and Science Fiction by Ursula K. Le Guin. Ed. Wood, Susan. New York: Perigee, 1979. 121-25.

McCaffery, Larry. "An Interview With Samuel Delany.” Across the Wounded Galaxies: Interviews with Contemporary American Science Fiction Writers. Ed. Larry McCaffery. Urbana: U of Illinois P, 1990. 71-104.

Myers, David. Bleeding Battlers from Ironbark: Australian Myths in Fiction and Film: 1890s-1980s. Rockhampton: Capricornia Institute, 1987. 
Penley, Constance. "Brownian Motion: Women, Tactics and Technology." Technoculture. Cultural Politics Vol. 3. Eds. Constance Penley, and Andrew Ross. Minneapolis: U of Minnesota P, 1991. 135-61.

Ross, Andrew. Strange Weather: Culture, Science and Technology in the Age of Limits. London: Verso, 1991.

Russ, Joanna. "The Image of Women In Science Fiction." Images of Women in Fiction: Feminist Perspectives. Ed. Susan Koppelman Cornillon. Bowling Green: Bowling Green U Popular P, 1972. 79-94.

Turner, Graeme. National Fictions: Literature, Film and the Construction of Australian Narrative. Sydney: Allen and Unwin, $2^{\text {nd }}$. Ed. 1993. 